\title{
El "lado oscuro" de la gobernanza del uso de suelo: las narrativas espacio- temporales y la neutralización del riesgo ambiental
}

\author{
Michael Scott ${ }^{1}$
}

\begin{abstract}
RESUMEN
El término gobernanza evoca procesos de negociación y colaboración entre la sociedad civil, el sector privado y los actores estatales. Sin embargo, los procesos de gobernanza también implican la competencia de valores en los esfuerzos por justificar la toma de decisiones respaldada por el Estado. Se investiga cómo las "técnicas de neutralización" se despliegan para desviar las críticas, gestionar la oposición y justificar nuevos y controvertidos proyectos de desarrollo inmobiliario costero, amenazados por el aumento del nivel del mar. La metodología consiste en 45 entrevistas en profundidad, semiestructuradas, con actores clave de la gobernanza del uso de suelo -desarrolladores, planificadores, políticos e ingenieros- en Australia Meridional. Se explora cómo aquellas técnicas se basan en metáforas espaciales tácitas, por lo que se plantea que una meta-técnica es deferir al tiempo para neutralizar discursivamente los riesgos ambientales proyectados para el espacio costero. Al hacerlo, se evitan cuestionamientos a la legitimidad de los sistemas de planificación del uso de la tierra. Estas técnicas cotidianas de neutralización espaciotemporal ofrecen una tipología inicial para un análisis comparativo del "lado oscuro" de la urbanización neoliberal global.
\end{abstract}

Palabras clave: Gobernanza, técnicas de neutralización, espacialidad, planificación, urbanización, costa.

\section{SUMMARY}

The term governance evokes processes of negotiation and collaboration between civil society, private sector, and state actors. Yet, governance processes also involve the contest of values in efforts to justify state-backed decision-making. Drawing on 45 semi-structured in-depth interviews with key land use governance actors - developers, planners, politicians, and engineers - in South Australia, this article investigates how 'techniques of neutralization' are reflexively deployed to deflect critiques, manage opposition, and justify contentious new coastal land developments threatened by sea-level rise. How these techniques draw on a tacit spatial metaphors is explored, proposing that a meta-technique is to defer to time to discursively neutralize the projected environmental risks to coastal space. In doing so, the legitimacy of land use planning systems is not called into question. These everyday spatiotemporal neutralization techniques offer an initial typology for further comparative analysis of the 'dark side' of global neoliberal urbanisation.

Keywords: Governance, techniques of neutralization, spatiality, planning, urbanisation, coast. 
La gobernanza es un concepto clave en las ciencias sociales (véase Bevir, 2010). Se entiende como los procesos intersectoriales e interorganizacionales de gestión en red, que conducen a una toma de decisiones en colaboración y de manera negociada (Rhodes, 1997). Para los investigadores socioespaciales, la gobernanza evoca imágenes del conocimiento oficial de la población y de sus actitudes, la econometría, el conocimiento técnico del espacio y de sus propiedades físicas, los procesos burocráticos formales e informales de definición de problemas y la creación de conocimiento a través de la participación de las partes interesadas para abordar cuestiones sociales urgentes. Esta interpretación de la gobernanza tiene una inflexión normativa. Cuando se efectúa correctamente, la gobernanza genera una toma de decisiones más equitativa, socialmente justa y consensuada, a través de la integración de las voces de las diversas partes interesadas y de la experiencia técnica.

Sin embargo, detrás de la gobernanza se esconde el proceso de "gobernar" (MacLeod \& Goodwin, 1999). Los sistemas jurídicos, las finanzas públicas, los intereses de las empresas y las racionalidades burocráticas a menudo ensombrecen los nobles objetivos normativos. La gobernanza como proceso surge, entonces, como un dominio de negociación y disputa dentro de las redes gestionadas por el Estado. Dentro de estos dominios, los actores promueven sus intereses al referirse al poder del estado, al conocimiento técnico o a normas sociales más amplias, y así crean narrativas para abogar por, o explicar las decisiones derivadas de la gobernanza. Tales narrativas merecen una mayor atención en el contexto del urbanismo neoliberal global. A medida que las lógicas del mercado se profundizan en el tejido socioespacial, y el estado y el capital forman nuevos enredos bajo lógicas de austeridad (Kane, 2019), la liberalización económica ve a los actores del sector privado facultados para amplificar la liberalización del mercado de la tierra, extender su influencia sobre la gobernanza del uso de la tierra y, por lo tanto, la (re)producción de la espacialidad urbana en todo el mundo (por ejemplo, Franz, 2017; Prinson \& Journel, 2017). Además, como estos modos neoliberales de gobernanza urbana son inestables y propensos a la "creatividad contradictoria" en la generación de resultados perversos, se pide a los actores en los procesos de gobernanza que justifiquen y legitimen las decisiones sobre el uso de la tierra que son contrarias a las creencias de la comunidad en general y a las normas sociales (Peck et al., 2013). En este caso, las prácticas de gobernanza implican formas tácitas de conocimiento para canalizar la información y moldear las percepciones, desviando las críticas y neutralizando la oposición.

Si bien reconoce el contexto neoliberal del desarrollo urbano, este artículo contrasta con los estudios de gobernanza del uso de la tierra que abogan por mejorar las relaciones basadas en la confianza (por ejemplo, Vallejos-Romero et al., 2016) o la adopción más plena del pensamiento adaptativo en la planificación (por ejemplo, Villagra et al., 2016). En cambio, se investiga el "lado oscuro" de la gobernanza del uso de la tierra (Flyvbjerg, 1996), bajo la pregunta de cómo tratan los actores de la gobernanza de justificar los nuevos desarrollos polémicos. Con este fin, se utilizan datos cualitativos en profundidad y la articulación de dos literaturas contrastantes: el concepto de las técnicas de neutralización discutido en la desviación sociológica y las teorizaciones de la espacialidad de la geografía humana. Aunque originalmente en los estudios de Sykes y Matza (1957) se profundizó en la delincuencia juvenil, la tipología de "técnicas de neutralización" ha demostrado ser duradera e intelectualmente productiva en investigaciones pertenecientes al estudio de los comportamientos que rompen con normas. Investigaciones recientes que han utilizado técnicas de neutralización en la investigación socioespacial consideraron prácticas de consumo éticas y sostenibles (por ejemplo, Johnston \& Tan, 2015), delitos contra la vida silvestre (Entico- 
tt, 2011), y responsabilidad social empresarial y producción industrial (por ejemplo, Boiral, 2015; Meyer \& Höllerer, 2016). Sin embargo, todavía no se han considerado las intersecciones entre la gobernanza y las técnicas de neutralización en el desarrollo inmobiliario. Esto es desconcertante ya que las técnicas de neutralización proporcionan un conjunto de herramientas políticas para justificar los desarrollos ambientalmente riesgosos sin cuestionar los impactos espacio-temporales a largo plazo de los sistemas de planificación del uso de suelo.

Este artículo se basa en material empírico de actores involucrados en el desarrollo inmobiliario en la costa de Australia Meridional. Como punto de encuentro entre la tierra y el mar, la costa ofrece múltiples usos humanos, incluyendo la recreación, la conservación y la estética. La costa de Australia significa un espacio sagrado de libertad donde se puede disfrutar del sol, la arena y el surf sin importar el estatus social (White, 1981). Además, la costa es un lugar para la valorización del capital a través del desarrollo inmobiliario, subrayado por el atractivo cultural de vivir junto al mar. Recientemente, ha habido un cambio radical en el que las regiones costeras y periurbanas han experimentado un crecimiento demográfico impulsado por "exiliados urbanos" que escapan de la inflación de los precios del suelo de los centros metropolitanos. Algunos se mudan permanentemente mientras que otros compran propiedades de "escapada de fin de semana" para experimentar la tranquilidad real o imaginaria de la vida en la costa (Burnley \& Murphy, 2003). Sin embargo, bajo el cambio climático acelerado antropogénicamente y el inminente aumento del nivel del mar, las mareas de tempestad afectan ahora a la costa con mayor frecuencia e intensidad, reclamando propiedad privada y pública, al tiempo que amenazan la infraestructura y los ecosistemas (Department of Climate Change, 2009). En consecuencia, la urbanización en curso y la continua conveniencia de estar en la costa crean presión sobre la gestión del alcance, la forma y la ubicación de las urbanizaciones costeras. Por lo tanto, la zona costera es un espacio intrínsecamente disputado y, por lo tanto, un sitio ejemplar para explorar las técnicas espacio-temporales de neutralización en la gobernanza urbana.

Este análisis se desarrolla en cuatro secciones. En primer lugar, se revisan los métodos cualitativos. En segundo lugar, se esbozan la planificación del uso de la tierra como institución de gobernanza, las técnicas de neutralización y la espacialidad. Luego, se ilustra cómo los actores adaptan las técnicas de neutralización por medio de narrativas espacio-temporales referentes a las dimensiones político-jurídicas, económicas e ideológicas del uso de la tierra costera. En la última sección se propone un meta-tema en estas técnicas de neutralización espacial la preferencia actual del tiempo en desmedro del espacio, y, en la conclusión, se señalan algunas implicaciones para el avance de la comprensión comparativa de la planificación y la gobernanza urbanas en todo el mundo.

\section{Metodología}

Esta investigación se enmarca dentro de un proyecto CSIRO que abarcó lugares por toda Australia (2010-13) con el fin de investigar las barreras sociales y culturales que impiden la asimilación del conocimiento científico en la toma de decisiones costeras. Con sede en el estado de Australia del Sur, mi grupo de investigación se centró en las instituciones de planificación del uso de la tierra, las redes sociales y las narrativas culturales dentro de estas. Al igual que otras regiones que utilizan la planificación para gestionar el riesgo ambiental (por ejemplo, Barton \& Irarrazaval, 
2016), Australia Meridional tiene un historial de uso de sistemas de planificación para gestionar su litoral, que varía desde las zonas de alta energía del Océano Austral hasta las aguas del golfo de baja energía. No solo fue el primer estado australiano en dar cuenta del aumento de nivel de mar en sus reveses de desarrollo (la distancia permitida entre el entorno construido y la zona costera), sino que también se le reconoce como poseedor de un sistema de planificación del uso de suelo transparente y relativamente incorrupto (Harvey \& Caton, 2010). El uso de la tierra costera está regulado por la Ley de Desarrollo (Government of South Australia, 1993), mientras que la Junta de Protección Costera (CPB por su sigla en inglés) supervisa la planificación y protección de las zonas costeras, y asesora y orienta al Ministro de Medio Ambiente, a la Autoridad Estatal de Planificación y a las Autoridades de los Gobiernos Locales (AGL o consejos locales) sobre los desarrollos costeros. En general, los gobiernos locales evalúan las propuestas de desarrollo con referencia a la sección pertinente del Plan de Desarrollo. Ellos deben tener en cuenta (pero no adherirse legalmente) a la política del PCB sobre reveses y peligros de inundaciones costeras (Coast Protection Board, 1991).

La recolección de datos empíricos comenzó en junio de 2011 con un focus group con el Departamento de Medio Ambiente y Recursos Naturales para identificar casos clave de desarrollos costeros expuestos al aumento del nivel del mar. Tras el focus group, se seleccionaron cuatro desarrollos recientes: un complejo de departamentos para jubilados y un re-desarrollo de un club de surf en la costa metropolitana de Adelaide (cuya extensa playa blanca se gestiona por medio de costosos carros de arena); un resort regional de vacaciones; y un gran desarrollo de un asentamiento periurbano en una planicie de inundación adyacente a las aguas del golfo metropolitano. Todos los casos fueron seleccionados sobre la base de que eran relativamente recientes (en los últimos 6 años), de manera que los entrevistados pudieran recordar los eventos y procesos. En lugar de comparar y contrastar los procesos específicos entre casos (para esto ver Scott \& Harvey, 2016; Scott et al., 2018) mi enfoque en este artículo es usar los datos de estas entrevistas sobre desarrollos costeros aprobados como un caso paradigmático (Flyvbjerg, 2001: 80). Aunque no son datos recientes, estas entrevistas ponen de relieve narrativas duraderas dentro de la gobernanza del uso de la tierra en las zonas costeras, donde el aumento proyectado del nivel de mar amenaza -y por lo tanto esclarece- las justificaciones ejemplares desplegadas por los actores de la gobernanza. Si estas técnicas de neutralización se utilizan en el contexto de Australia Meridional, donde el sistema de planificación es sólido y transparente, probablemente se aplicarían en otros lugares, es decir, dondequiera que los actores estatales y corporativos necesitasen legitimar el desarrollo urbano y las nuevas formas de uso de la tierra.

Las entrevistas se realizaron entre julio de 2011 y mayo de 2012. A partir del focus group inicial, sumado a una búsqueda de artículos de los medios de comunicación sobre los casos seleccionados (utilizando la base de datos "Factiva"), una búsqueda de documentos de políticas, planes de desarrollo, informes del CPB, presentaciones del gobierno local, material de la consultora Hansard de Australia del Sur, informes anuales de salvavidas del club de surf, borradores de planes y presentaciones de los desarrolladores se identificaron a 47 posibles entrevistados, de los cuales sólo dos se negaron a participar. En estas entrevistas semiestructuradas se pidió a los encuestados que relataran el caso y el proceso de desarrollo, los actores con los que se relacionaron y cómo el conocimiento científico se alineó dentro de los sistemas de planificación para informar la decisión final. Las entrevistas duraron entre 30 y 90 minutos, lo que permitió a los encuestados explicar en detalle sus experiencias en la gobernanza del uso de suelo. Las entrevistas fueron 
transcritas y analizadas utilizando Nvivo. Los datos se codificaron deductivamente según los temas de las técnicas de neutralización (discutidos más adelante) y luego se analizaron a fondo mediante referencia a la espacialidad.

\section{Planificación del uso del suelo, técnicas de neutralización y espacialidad}

\section{Planificación del uso de la tierra}

La planificación del uso de suelo requiere ser tratada en detalle, ya que es una institución fundamental para el desarrollo costero. Teóricamente, la planificación del uso de suelo crea derechos de propiedad. En la línea de Polanyi (1957), la tierra es una de las mercancías ficticias (las otras son el trabajo y el dinero), ya que no se presta fácilmente a la mercantilización y, por lo tanto, al intercambio en la economía de mercado neoliberal. Además, la tierra no puede ser expropiada sin el riesgo de degradación, externalidades negativas o consecuencias no deseadas en las áreas adyacentes. La formalización del derecho de propiedad y de las burocracias de planificación es necesaria para garantizar la continuidad de los usos sociales de la tierra y su futura valorización a través del intercambio de mercado (Harvey, 1978). En contextos urbanos globales, el desarrollo de la tierra ocurre a menudo a través de "coaliciones de crecimiento" que incluyen a los promotores inmobiliarios y a los gobiernos (Logan \& Molotch, 2007; Lukas \& Fragkou, 2014). Es importante destacar que la planificación del uso de suelo es una de las pocas palancas de desarrollo económico disponibles para los estados australianos que operan bajo las presiones económicas interlocales del federalismo competitivo.

Al dividir la superficie de la tierra bajo la autoridad del estado, la planificación crea diferentes zonas. La planificación del uso de suelo se trata de "qué va adonde" (Taussik, 2007). Las zonas regulan el desarrollo construido -o las protecciones- que ocurren en ese espacio. Sin embargo, la zonificación y el desarrollo no es un procedimiento tecnocrático de la alta planificación modernista. En cambio, esta institucionalización significa que la planificación está llamada a cumplir "objetivos concretos, múltiples y determinados que podrían contener varios procesos sociales simultáneamente" (Krippner, 2002: 804), incluyendo el resultado final triple ("triple bottom line" en la bibliografía en inglés) de los beneficios sociales, económicos y ambientales (Elkington, 1999). Como tal, la planificación no necesariamente predetermina los fines del desarrollo. Los nuevos desarrollos involucran la gobernanza, que une los procesos legales que asignan derechos con las evaluaciones sociales de los riesgos y beneficios del desarrollo propuesto. Aquí, los actores estatales y los planificadores de los gobiernos locales coordinan una serie de poseedores de conocimientos: ingenieros, científicos, políticos, grupos comunitarios, ONG y otras partes interesadas en el sitio y sus usos adyacentes.

Las organizaciones de planificación estatal también establecen los procesos debidos, que son un juego y una estructura de incentivos para participar (North, 1990). Los múltiples usos de la tierra significan que ninguna política de planificación puede cubrir todas las contingencias que pueda presentar una propuesta de desarrollo, ni tener en cuenta las condiciones ambientales bajo las cuales se proponen los desarrollos. Hay un "arte oscuro" en aprobar el desarrollo del uso de la tierra en sitios controvertidos. Aquí, actores conocedores y reflexivos participan en 
negociaciones, canalizan la información, explotan relaciones de poder asimétricas y manipulan la información, al tiempo que reúnen hábilmente diversas formas de evidencia para apoyar o criticar la propuesta de desarrollo. Debido a que el futuro es algo relativamente desconocido, las decisiones de desarrollo pueden ser apoyadas en múltiples modalidades -económicas, socioculturales o ambientales- sin que ninguna forma de conocimiento sea el árbitro final, lo que los asesores de planificación llaman "una decisión equilibrada". En este espacio discursivo para narrativas heterogéneas, pero socialmente aceptables, las técnicas de neutralización emergen como un medio para validar discursivamente los desarrollos contenciosos.

\section{Técnicas de neutralización y espacialidad}

Sykes y Matza (1957) desarrollaron el concepto "técnicas de neutralización" en la sociología de la desviación para diferenciar las narrativas usados por "los delincuentes" para justificar su comportamiento violatorio de normas y leyes. Argumentan que estas técnicas permiten a los "delincuentes" reconciliar las demandas conflictivas de su subcultura primaria con las normas sociales externas de la comunidad. Estas técnicas de neutralización sirven para excusar las acciones por medio del desvío, la remodelación y la reformulación de las críticas del sistema de justicia y de la sociedad. Entre ellas se incluyen:

1. Negación de responsabilidad: apelar a fuerzas externas fuera del control del actor. Las lesiones son producidas por las circunstancias y se niega la responsabilidad personal a través de la afirmación de ser impulsado sin esperanza a situaciones conflictivas.

2. Negación de la lesión: gira en torno a la distinción entre "actos que son incorrectos en sí mismos y actos que son ilegales pero no inmorales" (Sykes \& Matza, 1957: 667). A pesar de ser contraria a las normas sociales, la acción no causa daños significativos, como graffitis o peleas.

3. Negación de la víctima: cuando el delincuente acepta la responsabilidad de sus acciones, la víctima puede ser negada. Cualquier lesión es minimizada ya que la víctima podría haberla "merecido" o si el delito es contra la propiedad y no hay daño físico.

4. La condena de los condenadores: desvía las reclamaciones contra los que desvian de la norma trasladando la duda sobre los motivos y comportamientos de los que las desaprueban. Aquellos que defienden las normas de la sociedad, se consideran cínicos, calificándolos de hipócritas egoístas.

5. Apelar a lealtades más elevadas: articular una devoción por los subgrupos más pequeños que se consideran más importantes que la sociedad en general: la familia, los amigos y las pandillas.

Al esbozar estas técnicas neutralizadoras, Skyes y Matza (1957) no sugieren que ninguno de ellos posea la máxima eficacia o tenga más peso para influir en los resultados de la justicia. En cambio, las técnicas de neutralización ponen en duda los argumentos de un oponente mientras permiten que el autor del error se identifique con las normas sociales. Al proporcionar una racionalización del comportamiento desviado en función del contexto, permiten que los actores se desplacen entre sistemas de valores - normas sociales más amplias y valores subculturales (Mooney 2007).

Estas técnicas de neutralización se utilizan a menudo para desviar las críticas y justificar los desarrollos costeros. En este medio, tales técnicas se espacializan tácitamente. La espacialidad 
es un concepto fundamental debatido en la geografía humana, que en general se refiere a cómo el espacio y el tiempo co-constituyen dialécticamente las producciones sociales, culturales y "cuasimateriales" de lugar, medio ambiente, paisaje y región (Merriman et al., 2012: 4; Massey, 2005). Para facilitar el análisis, adopto una interpretación materialista de la espacialidad reconociendo que el espacio geográfico "se produce socialmente, existe tanto en formas sustanciales (espacialidades concretas) como en un conjunto de relaciones entre individuos y grupos, una "encarnación" y un medio de la vida social misma" (Soja, 1989: 120). En términos generales, una espacialidad materialista enfatiza el espacio como espacio capitalista. Se constituye a través de un conjunto de dominios superpuestos (Lefebvre \& Nicholson-Smith, 1991):

1) Lo político-jurídico, es decir, las instituciones tecnocráticas que crean representaciones abstractas del espacio tales como la planificación y la subdivisión, el conocimiento científico, y los sistemas políticos que crean escala y territorio.

2) La espacialidad económica en la que el lugar es un sitio para la valorización de la tierra como una mercancía para la inversión y los beneficios a largo plazo, y como un lugar moldeado por y para la dialéctica de la producción y el consumo.

3) La espacialidad ideológica que implica las representaciones simbólicas del espacio para ocultar la característica capitalista del uso de la tierra. Aquí la costa puede simbolizar creencias como "libertad", para "la gente", "la naturaleza", o de "progreso" y "desarrollo".

Ningún dominio es determinante; el espacio contiene una multiplicidad de usos y significados sociales potenciales. La espacialidad es también paradójica: es producida por diferentes formas de conocimiento y, por lo tanto, es simultáneamente conocible e incognoscible (Kitchin, 2009). Esta espacialidad caleidoscópica crea numerosas oportunidades para desplegar las técnicas de neutralización espacial contra la creencia normativa australiana de que el cambio climático (y por lo tanto el aumento del nivel del mar) está ocurriendo y que se deben tomar medidas (Leviston et al., 2011).

\section{Técnicas espacio-temporales de neutralización}

\section{Negación de responsabilidad: estructuras político-jurídicas}

Los actores de la gobernanza del uso de la tierra costera reconocen las estructuras político-jurídicas sobre las que se basan sus acciones. Esto puede frustrar, obstruir o limitar los esfuerzos para incorporar medidas de protección, alterar las propuestas de desarrollo o poner fin a las protecciones ambientales prudentes. En su forma espacial, la negación de responsabilidad es un aplazamiento de procesos de planificación más amplios, sus limitaciones burocráticas y las lógicas pro-desarrollo de las coaliciones de crecimiento. Para neutralizar las quejas sobre el desarroIlo costero, los planificadores estatales que realizan las evaluaciones finales utilizan esta técnica. Los planificadores justifican sus decisiones por su posición dentro del espacio tecnocrático de los procesos de gobernanza, narrando que su acción está limitada por regulaciones de planificación externa fuera de su control.

“... no diseñamos el desarrollo, no seleccionamos la ubicación, sino que obtenemos una copia de la aplicación con el diseño, y eso determina la naturaleza del desarrollo y el proceso de aplica- 
ción que seguimos. Hacemos la evaluación sobre esto contra el plan, y luego hacemos recomendaciones para aceptar, enmendar o rechazar la solicitud" (Planificador Estatal).

"... el documento [de la zona de uso de la tierra] puede ser viejo, deficiente, muy general, puede no estar redactado de una manera que sea fácilmente comprensible, puede estar abierto a la interpretación... no importa. Eso es lo que tenemos y con lo que tenemos que trabajar" (Planificador Estatal).

Aquí, la negación de la responsabilidad por futuros impactos ambientales se conjura a través de la referencia al debido proceso: al no tener esperanza, impulsado por un procedimiento formal, se puede defender una decisión equilibrada con respecto a un desarrollo arriesgado. Una crítica enérgica de este modo de neutralizar es que limita la contabilización de las excepciones. Esto es presentado por actores menos centrales en la toma de decisiones sobre el desarrollo costero-científicos e ingenieros que proporcionan asesoramiento experto:

"... [los planificadores y burócratas] marcan cumplimiento de puntos en una lista de verificación...si se alejarían de la mentalidad de la lista e interactuarían para trabajar hacia una decisión, en otras palabras, se involucrarían en un proceso en lugar de ser la policía del proceso, entonces creo que tendrán un resultado mucho mejor" (Consultor, científico ambiental).

En general, esa neutralización espacial desvía los riesgos ambientales futuros que no pueden gestionarse en el ámbito político-jurídico existente de la evaluación de la planificación. El espacio costero se rehace dentro de las temporalidades tecnocráticas de los procesos de planificación que priorizan un presente económico sobre un futuro ambiental prudente. Paradójicamente, suponiendo que las proyecciones del aumento del nivel del mar sean correctas, el cumplimiento del valor monetario privado de la costa impone mayores costos de protección socializados. La costa como espacio económico se superpone a la negación de responsabilidad.

\section{Negación del daño y de la víctima: legitimar la espacialidad económica}

El uso continuo de la costa como espacio económico está implícito en la planificación. Materialmente, los nuevos desarrollos benefician los intereses privados a través de la apreciación del precio de suelo, a los gobiernos locales a través de la mayor recaudación de impuestos, mientras que centros de recreación como los clubes de salvaguardias de surf tienen externalidades económicas y sociales positivas al crear espacios de consumo. Por lo tanto, un planificador urbano del gobierno local que busca implementar un desarrollo costero prudente reconoce las presiones económicas para hacer que el espacio costero esté siempre disponible para el desarrollo (negando al mismo tiempo la responsabilidad):

"Las barreras [a la implementación de protecciones ambientales o al bloqueo del desarrollo costero] son las pobres políticas de estado para la costa [es decir, jurídicamente débiles]. No tenemos mucho para detener el desarrollo. Realmente no hay nada en ninguna de las políticas del gobierno estatal que tenemos a disposición para poner en nuestro plan de desarrollo, que detenga el desarrollo. El desarrollo siempre va a suceder, pero es cuestión de mitigar los problemas que lo acompañan. No podemos hacer más que eso. No existe una política para restablecer las dunas cuando una casa llega al final de su vida útil." 
Para mitigar las normas paradójicas -la gobernanza del uso de suelo como protección de la propiedad contra el riesgo ambiental, la gobernanza como habilitadora del desarrollo urbanístico-, la negación del daño y la negación de la víctima se superponen. Ambos crean una distinción entre las acciones que son incorrectas en sí mismas y las acciones que son "incorrectas" pero no inmorales: no se desarrollan argumentos de daño físico o individual significativo. Cuando se despliegan en sitios donde el aumento proyectado del nivel del mar tendrá un impacto en los nuevos desarrollos, estas técnicas niegan lesiones y víctimas futuras a través de la referencia a un grupo social más amplio y difuso. El aumento del mar impactará a otras comunidades, así que ¿por qué restringir el desarrollo en este sitio? Por ejemplo, un concejal del gobierno local partidario del desarrollo rechazaba las proyecciones del aumento del nivel del mar haciendo referencia a otras comunidades potencialmente afectadas:

“... pero gran parte del proyecto [de desarrollo municipal] está por encima de lugares como la Península [industrial y residencial adyacente], que en realidad están por debajo de los niveles en los que se encuentra la mayor parte de este desarrollo. Así que si tenemos problemas con la subida del nivel del mar, iserá después de que afecte a muchas otras áreas!."

De la misma manera, un representante de un club de surf que había trabajado en estrecha colaboración con actores políticos estatales, racionaliza el desarrollo actual a través de una dimisión temporal:

"... hemos hecho lo que hemos podido para respetar lo que dijo el [planificador estatal]. Uno de sus comentarios fue que las olas de tres metros golpearán el edificio. Si eso sucede, entonces toda la costa metropolitana estará en peligro, así que no puedes prepararte contra eso. Aunque pueda sonar ridículo para los que viven aquí, simplemente no se puede evitar que eso suceda y que todo el estado se vea amenazado, no solo nosotros. Le dije: ,Si sientes que nuestro edificio está bajo ese tipo de peligro, entonces es mejor que le digas a todos los que viven a lo largo de la costa que vendan ya y que no esperen que sus hijos vayan a heredar la casa en el paseo marítimo iporque ya no estará alli!'." (Promotor privado)

Tales declaraciones podrían interpretarse como una negación de la capacidad -la inevitabilidad de que la subida de nivel del mar no puede ser impedida. Sin embargo, esta negación de la víctima y del daño invoca una socialización tácita. Las lesiones proyectadas de los nuevos desarrollos se analizan a través de llamamientos a una comunidad costera generalizada, presente y futura. Si todos en la costa se verán afectados, no hay una víctima o lesión específica. Hay un desastre. Por lo tanto, el uso actual de la costa como espacio económico puede ser legitimado ampliando la base de víctimas, que se difunde aún más a través de la referencia a la incertidumbre futura. Los debates sobre la costa como espacio económico se amplían luego a enfrentamientos ideológicos entre actores pro- y anti-desarrollo, y a la condena de los que los condenan.

\section{La condena de los condenadores: la espacialidad ideológica I}

Esta técnica es un descarado "rechazo de los rechazadores" (Sykes \& Matza, 1957: 668). Pone en tela de juicio los motivos y los comportamientos de quienes lo desaprueban. Esto podría ser una desaprobación sobre los acontecimientos o una desaprobación sobre las posiciones de desarrollo proambiental/moderado dentro de los entornos de gobernanza. Estas técnicas fueron 
ampliamente articuladas. Dos ejemplos indicativos de parlamentarios a favor y en contra del desarrollo ilustran cómo los intereses ideológicos -y el imaginado potencial de la costa- están condenados a justificar el desarrollo inmediato:

"Si algo sé con certeza, es que metí a media docena de científicos (costeros) en esta sala. Podríamos llegar a seis puntos de vista diferentes y en lo único que todos estarán de acuerdo es en la necesidad de más fondos para la investigación. Lo que vemos a menudo es a los científicos enfrentados entre sí en vez de en una posición acordada. Los defensores de no hacer nada siempre dirán 'pero necesitamos más investigación '." (Diputado del Estado)

Mientras que un diputado estatal que se opone a la expansión urbana y a la amplificación neoliberal de los mercados de tierras toma nota:

"He dado muchos discursos en el parlamento sobre el conflicto de intereses (el gobierno del estado) bajo la Investigación de Áreas de Crecimiento. [Los planificadores del sector privado] realizaron la gran parte del estudio para el gobierno sobre las áreas de crecimiento en las afueras de la ciudad [incluyendo las zonas costeras]. Hicieron ese trabajo para el gobierno y al mismo tiempo representaban a promotores privados que habian estado comprando tierras en los márgenes [de la ciudad]. Entonces, ivaya sorpresa!, resulta que recomendaron al gobierno que las áreas que sus clientes poseían eran adecuadas para el desarrollo urbano." (Diputado del Estado)

Dentro de las prácticas de gobernanza supuestamente transparentes, los motivos de los opositores se condenan haciendo visibles el interés propio y llamando a la rendición de cuentas. En términos generales, los grupos a favor del desarrollo pueden condenar señalando la naturaleza paradójica de la costa -es conocida y desconocida-, mientras que los grupos contrarios al desarrollo condenan las disyuntivas temporales de la coalición para el crecimiento que privatizan los beneficios y socializan los costes. En los debates sobre la gobernanza, éstas ofrecen posiciones contrapuntísticas duraderas. Una estrategia similar se aplica a los llamamientos a las lealtades más elevadas.

\section{Llamamiento a las lealtades superiores: la espacialidad ideológica II}

En la literatura de la sociología de la desviación, las apelaciones a las lealtades más elevadas se refieren a las pandillas, las hermandades o la familia inmediata cuyos intereses están por encima de la ley o de las normas sociales. Este enfoque actúa entonces mediante la referencia a un sistema de valores alternativo llevado por subgrupos. En su forma espacial esto ocurre a través del privilegio de subgrupos a escalas ideológicas opuestas. Una iteración de esta técnica es desplazar las críticas sobre los riesgos ambientales a través de una reivindicación de la mayor lealtad de la comunidad local como escala ideológicamente privilegiada. Aquí, un concejal de las autoridades de los gobiernos locales favorable al desarrollo mezcla la condena de los que condenan con las altas lealtades inmediatas de la comunidad local:

“... debido a que esta minoría vocal [refiriéndose aquí a los activistas ambientales de la comunidad] maneja las cosas, la burocracia [de planificación] los escucha. Pero no solo tuvimos a la minoría vocal, sino a toda un espectro de personas que forman lo que yo llamo "la gente real", y no 
solo a activistas autoproclamados. Como decía, trabajo con la gente. Los activistas son vocales y deshonestos." (Concejal del gobierno local)

Una alternativa de mayor lealtad es la creencia en la ciencia y la acción comunicativa racional. Este subgrupo muestra lealtad a la experiencia especializada, pero esta se cuestiona cada vez más en el discurso público y político de la posverdad (véase Kelly \& McGoey, 2018). Sin embargo, una mayor lealtad a las autoridades científicas mundiales puede influir en las decisiones de planificación, teniendo en cuenta las predicciones de la subida del nivel del mar:

"Hay escepticismo público, pero si se presenta un proyecto, como el proyecto [de centros turísticos costeros] o algo así y se incluye en la información que se han considerado las directrices del IPCC (Grupo Intergubernamental de Expertos sobre el Cambio Climático) y cosas por el estilo, estas recomendaciones que se presentan van a los departamentos del gobierno o al consejo local o algo así. $Y$ aunque puede haber mucho escepticismo en la comunidad en general, eso no pasa con los departamentos del gobierno o del consejo local." (Ingeniero consultor)

Los llamados a una mayor lealtad -o a otras técnicas de neutralización- no son garantía de éxito en el logro de los objetivos. Surgen en un proceso de planificación en terreno en el que los debates descienden en una serie de tropos de gobernanza o maniobras rituales para señalar y pedir cuentas de las acciones de los oponentes, mientras mantienen la autoimagen de los actores. Dentro de estos ejemplos hay, por supuesto, deslices entre las narrativas y las prácticas, líneas borrosas de autoridad y condena, y múltiples e imperfectos caminos hacia la justificación dentro de la gobernanza costera. También hay redes de gobernanza en evolución, tensión permanente entre el conocimiento técnico, la sociedad y los valores de la comunidad, y los sistemas de planificación, y las incesantes presiones económicas sobre el uso de la tierra, que hacen de la gobernanza un proceso de negociación gestionado por el Estado. En este contexto, las técnicas de neutralización espacializadas no son más que un componente de un conjunto de herramientas tácitas. En estos ejemplos, las justificaciones que proporcionan las técnicas de neutralización son interdependientes y co-emergentes, y son intentos de reconciliar discursivamente las contradicciones del espacio costero. Proporcionan una serie de herramientas políticas que justifican (y cuestionan) las acciones de desarrollo que son contrarias a las normas sociales que valoran la adaptación a los riesgos climáticos. Lo que estas técnicas sugieren entonces es una meta-narrativa espacial: la neutralización del espacio a través de la referencia al tiempo.

\section{¿Neutralizar el espacio a través del tiempo?}

Para los geógrafos humanos la dialéctica espacio-tiempo es un tema central y un paradigma organizador. Sin embargo, estos dos conceptos no son los mismos en las narrativas académicas, ni en las narrativas cotidianas. Como sostiene Soja (1989), muchas veces el espacio es subsumido al tiempo: el tiempo es activo y devenir, el espacio está muerto e inerte -la cristalización física del tiempo. En estudios sobre el capitalismo global, como el de Harvey (1989), la dinámica de acumulación del capital funciona a través de la aniquilación del espacio inerte (distancia) por el tiempo a través de las nuevas tecnologías y la convergencia institucional, mientras que la tierra proporciona simultáneamente una "solución espacial" a las rondas de inversión de capital. Massey 
(2005: 71) es más moderada en sus afirmaciones, pero considera que la dialéctica espacio-temporal es co-constituyente:

"Aquí la representación del espacio tiene lugar a través de su convocatoria a una secuencia temporal. El desafío del espacio es abordado por la imaginación del tiempo... [la modernidad es un espacio visto a través del tiempo]. La verdadera importancia de la espacialidad, la posibilidad de múltiples narraciones, se perdió. La regulación del mundo en una sola trayectoria, a través de la convocatoria temporal del espacio, fue, y sigue siendo a menudo, una forma de negarse a abordar la multiplicidad esencial de lo espacial. Es la imposición de un único universal" (traducción propia).

Una implicación del argumento de Massey es que este privilegio modernista del tiempo sobre el espacio se convierte en técnicas espaciales de neutralización. En este conocimiento cuasi-folk de la gobernanza costera, el espacio fue descrito como "indiferente al tiempo". Independientemente de sus historias espaciales relacionales, el espacio costero fue relatado principalmente como un lugar físico para ser reconstruido para usos inmediatos o futuros. Un concejal del gobierno local a favor del desarrollo resume esta ética de tiempo y espacio:

"... ¿Se va a acabar el mundo por esto [el desarrollo costero]? No. Entonces, i ipara qué preocuparse por lo que vaya a hacer el nivel del mar?! No tiene relevancia para mi día a día, ni para lo que puede suceder en la próxima generación. No nos importa lo suficiente la siguiente generación, lo que venga después de eso."

Asimismo, el desarrollo histórico y los intereses privados hacen que un ingeniero costero recurra a futuros niveles de experiencia y financiación pública para defender la costa. El tiempo ahorra espacio (y capital):

“... solo hay que hacer un cálculo rápido del valor de la propiedad frente al mar y luego llegar a la conclusión -y estos lugares valen más de un millón de dólares australianos por cada 15m de fachada. Una vez que hayas [conseguido que el gobierno implemente una retirada de la estrategia frente a la subida de nivel del mar], comprado esto, ¿qué pasa con la siguiente fila? El mar no se detiene ahí. Así que cientos de hectáreas de tierra detrás de la primera fila están sujetas a inundaciones, aunque se renuncie a las propiedades de la primera fila. No se trata de una o dos filas de casas, se trata de retroceder un par de kilómetros de terreno inundable en la costa -es ridículo pensar que nos retiraremos. Desde el punto de vista estructural que usted defiende... seguiremos con lo que los holandeses vienen haciendo durante los últimos 100 años."

Se necesita tiempo para neutralizar los riesgos del desarrollo costero mediante el despliegue de reclamos sobre un futuro espacial desconocido. A pesar de la creciente sofisticación de la modelación computacional de la decisión de agentes, la lógica temporal de la economía monetaria no puede tener en cuenta todos los efectos espaciales futuros. El aumento del nivel del mar y el cambio climático son desconocidos, ya que se basan en proyecciones difusas (Whatmore, 2009) y en la especificidad geomorfológica local (Scott \& Harvey, 2016), por lo que la gobernanza del uso de la tierra está atormentada por la pregunta "ipor qué dejar para mañana lo que puedes hacer hoy?" No hay certeza sobre el futuro ambiental o sociopolítico, por lo que a este futuro no se le puede dar preferencia sobre el presente. Además, en el contexto del urbanismo neoliberal de Australia Meridional, los planificadores y los políticos no tienen tiempo para esperar el desarrollo 
económico: es necesario tomar medidas ahora. Si el espacio costero se ve amenazado por la subida del mar, se debe actuar sobre él cuando esté dotado de niveles de ingeniosidad humana y financiación humanos que aún no se han manifestado, respaldados por nuevos modos de gestión costera consensuada. El espacio fijo es neutralizado por el tiempo fluido.

Estas técnicas de neutralización espacializadas no son solo racionalizaciones cognitivas, sino herramientas políticas que intentan reconciliar las contradicciones de la gobernanza del uso de la tierra (Fooks et al., 2013). Al apaciguar la crítica, las técnicas de neutralización espacializadas funcionan dentro de una narrativa modernista. En este sentido, los actores de la gobernanza no pueden controlar el pasado, pero pueden apelar a un futuro controlado colectivamente. Este privilegio del tiempo requiere simultáneamente comunidades específicas y beneficios sociales más amplios, beneficios materiales inmediatos y futuros, e implica que el espacio costero es domesticable, independientemente de los riesgos geofísicos inminentes. Estos llamamientos a la neutralización del tiempo neutralizan las preocupaciones sociales más amplias con respecto al cambio climático y la subida del nivel del mar sin cuestionar la legitimidad de la gobernanza de las tierras costeras. Ideológicamente, estas técnicas espacio-temporales de neutralización eluden las presiones político-económicas y la "creatividad contradictoria", sobre las que se basa y realiza el desarrollo urbano neoliberal (Peck et al., 2013), justifican la resolución de las crisis de uso de la tierra mientras producen crisis de uso de la tierra.

\section{Conclusión}

Este análisis de las técnicas de neutralización espacializadas pone de manifiesto un problema metodológico. Las entrevistas se realizaron post-factum y, por lo tanto, según Bourdieu (2004), cuando los actores entrevistados crean historias que son semi-teóricas o que buscan impresionar al entrevistador, a la vez presentan una imagen e identidad particular del participante -una que se ajusta a su propia imagen. Si estas técnicas y metáforas espaciales se utilizan en prácticas de gobernanza in situ o solo surgen como racionalizaciones en las entrevistas posteriores al evento, es un área que requiere investigación adicional. También lo es la forma en que los actores de la gobernanza del uso de suelo buscan desplegar y contrarrestar las técnicas de neutralización tanto en la aprobación del desarrollo como en el rechazo de las propuestas de desarrollo.

Sin embargo, este artículo ha tratado de dilucidar aún más el "lado oscuro" de la gobernanza a través de un estudio de las narrativas desplegadas en el uso de la tierra costera. Al traer técnicas de neutralización de la sociología de la desviación a los contextos de gobernanza, se pusieron en primer plano las formas subversivas de conocimiento. Co-situado dentro del proceso formal, técnico y racional del desarrollo del espacio es un conocimiento tácito de cómo justificar las decisiones de planificación derivadas de la gobernanza. Estas utilizan imágenes y metáforas espaciales para crear narrativas neutralizadoras: negación de responsabilidad en las presiones formales del dominio político-jurídico; negación de lesiones y víctimas a través de referencias a otros espacios costeros que legitiman la costa como espacio económico; y uso de ideologías de espacio y escala que compiten entre sí para enmarcar la condena de los que condenan o apelan a mayores lealtades. Estos esfuerzos rituales para neutralizar normas sociales más amplias que reconocen los privilegios del cambio climático antropogénicamente acelerado privilegian el tiempo sobre 
el espacio, desviando la atención de los acuerdos de gobernanza materialistas que permiten que ocurra un desarrollo costero arriesgado.

Queda por ver si este argumento de destacar las técnicas de neutralización espacializadas en los urbanismos neoliberales es una rareza local o si tiene resonancia analítica a nivel global. Con el crecimiento de los regímenes "neoextractivistas" -tanto de los recursos "naturales" como del espacio urbano- a lo largo de América Latina, hay margen para explorar en mayor profundidad cómo, dónde y cuándo se articulan las técnicas de neutralización. Y no solo por los planificadores urbanos, sino también en los momentos en que las corporaciones globales (desde la minería hasta los agroindustriales), los promotores inmobiliarios y los políticos locales y nacionales tratan de sacar provecho del espacio. La construcción de casos comparativos globales de las justificaciones dentro de la gobernanza del uso de la tierra podría informar el siguiente paso político: la neutralización de la neutralización.

\section{Agradecimientos}

Esta investigación fue financiada por el CSIRO Coastal Collaboration Cluster (2010-2013). Quisiera agradecer a Johannes Glückler Johannes Rehner y Michael Handke por la invitación a presentar este número especial. Los comentarios de dos revisores anónimos y asistentes a los seminarios que impartí en la Pontificia Universidad Católica, el Departamento de Geografía y el Centro Heidelberg para América Latina, en septiembre de 2018, ayudaron a refinar el argumento presentado aquí. Las discusiones informales con Michael Handke, Michael Lukas y Enrique Aliste proporcionaron más contexto.

\section{Bibliografía}

BARTON, JR. \& IRARRAZAVAL, F. Adaptación al cambio climático y gestión de riesgos naturales: buscando síntesis en la planificación urbana. Revista de Geografía Norte Grande, 2016, № 63, p. 87-110. http://dx.doi.org/10.4067/S0718-34022016000100006.

BEVIR, M. (editor). The SAGE Handbook of Governance. Thousand Oaks: Sage, 2010.

BOIRAL, O. Strategies for Climate Change and Impression Management: A Case Study Among Canada's Large Industrial Emitters. Journal of Business Ethics, 2015, № 132, p. 329-346. http://dx.doi. org/10.1007/s10551-014-2322-5

BOURDIEU, P. Science of science and reflexivity. Cambridge, UK: Polity Press, 2004.

BURNLEY, I., \& MURPHY, P. Sea change: Movement from metropolitan to Arcadian Australia. Sydney: UNSW Press, 2003.

COAST PROTECTION BOARD. Policy on coast protection and new coastal development. Adelaide: Government of South Australia, 1991. 
DEPARTMENT OF CLIMATE CHANGE. National coastal assessment. 2009. Retrieved from www. climatechange.gov.au/government/initiatives/australias-coasts-and-climate-change/adapting/ national-coastal-risk-assessment.aspx

ELKINGTON, J. The triple bottom line: Sustainability's accountants. In RUSSO, M. (editor) Environmental management: Readings and cases. Thousand Oaks; Sage, 1999, p. 49-66.

ENTICOTT, G. Techniques of neutralizing wildlife crime in rural England and Wales. Journal of Rural Studies, 2011, № 27, p. 200-208. https://doi.org/10.1016/j.jrurstud.2011.01.005

FLYVBJERG, B. The Dark Side of Planning: Rationality and 'Realrationalität'. In MANDELBAUM S., MAZZA, L., \&. BURCHELL, R.W. (editors). Explorations in Planning Theory, New Brunswick, NJ: Center for Urban Policy Research Press, 1996, p. 383-394. Available at SSRN: https://ssrn.com/abstract $=2278431$

FLYVBJERG, B. Making social science matter: Why social inquiry fails and how it can succeed again. Cambridge, UK: Cambridge University Press, 2001.

FOOKS, G., GILMORE, A., COLLIN, J., HOLDEN, C. \& LEE, K.. The limits of corporate social responsibility: techniques of neutralization, stakeholder management and political CSR. Journal of business ethics, 2013, No 2, p. 283-299. https://doi.org/10.1007/s10551-012-1250-5

FRANZ, T. Urban governance and economic development in Medellín: an urban miracle? Latin American Perspectives, 2017, no. 2, p. 52-70. https://doi.org/10.1177/0094582X16668313

GOVERNMENT OF SOUTH AUSTRALIA: Development Act, 1993. Avaiable at: http://www.legislation. sa.gov.au/LZ/C/A/Development\%20Act\%201993.aspx

HARVEY, D. The urban process under capitalism: a framework for analysis. International Journal of Urban and Regional Research, 1978, № 2, p. 101-131. https://doi.org/10.1111/j.1468-2427.1978. tb00738.x

HARVEY, D. The condition of postmodernity. Oxford: Blackwell, 1989.

HARVEY, N. \& CATON, B. Coastal management in Australia. Adelaide: University of Adelaide Press, 2010.

JOHNSTON, M-L. \& TAN, L. An exploration of environmentally-conscious consumers and the reasons why they do not buy green products. Marketing Intelligence \& Planning, 2015, №33, p. $804-$ 825. https://doi.org/10.1108/MIP-09-2013-0159

KELLY, A. H. \& MCGOEY, L. Facts, power and global evidence: a new empire of truth. Economy and Society, 2018, № 47, p. 1-26. https://doi.org/10.1080/03085147.2018.1457261 
KANE, G. L. Lost promises: Debt, austerity, and development in Latin America. London: Routledge, 2019.

KITCHIN, R. Space II. In KITCHIN, R., \& THRIFT, N. (editors) International encyclopaedia of human geography. New York, NY: Elsevier, 2009, p. 268-275.

KRIPPNER, G. The elusive market: Embeddedness and the paradigm of economic sociology. Theory and Society, 2002, №30, p. 775-810. https://doi.org/10.1023/A:1013330324198

LEFEBVRE, H. \& NICHOLSON-SMITH, D. The production of space. Blackwell: Oxford, 1991.

LEVISTON, Z., LEITCH, A., GREENHILL, M., LEONARD, R. \& WALKER, I. Australians' views of climate change. Canberra: CSIRO, 2011.

LOGAN, J. R. \& MOLOTCH, H. Urban fortunes: The political economy of place. Berkley: University of California Press, 2007.

LUKAS, M. \& FRAGKOU, M. C. Conflictividad en construcción: desarrollo urbano especulativo y gestión del agua en Santiago de Chile. Ecología política, 2014, № 47, p. 67-71. http://www.jstor. org/stable/43528414

MACLEOD, G. \& GOODWIN, M. Space, scale and state strategy: rethinking urban and regional governance. Progress in Human Geography, 1999, № 23, p. 503-527. https://doi. org/10.1191/030913299669861026

MASSEY, D. For space. Thousand Oaks: Sage, 2005.

MERRIMAN, P., JONES, M., OLSSON, G., SHEPPARD, E., THRIFT, N., \& TUAN, Y. F. (2012). Space and spatiality in theory. Dialogues in Human Geography, 2012, № 2, p. 3-22. https://doi. org/10.1177/2043820611434864

MEYER, R. \& HÖLLERER, M. Laying a smoke screen: Ambiguity and neutralization as strategic responses to intra-institutional complexity. Strategic Organization, 2016, No 14, p.373-406. https:// doi.org/10.1177/1476127016633335

MOONEY, J. Shadow values, shadow figures: real violence. Critical Criminology, 2007, № 15, p. 159-170. https://doi.org/10.1007/s10612-007-9023-7

NORTH, D. C. Institutions, institutional change and economic performance. Cambridge, UK: Cambridge University Press, 1990.

PECK, J., THEODORE, N. \& BRENNER, N. Neoliberal urbanism redux? International Journal of Urban and Regional Research. 2013. №3, p. 1091-1099. https://doi.org/10.1111/1468-2427.12066

PINSON, G., \& JOURNEL, C. (eds). Debating the neoliberal city. London: Taylor \& Francis: 2017. 
POLANYI, K. The great transformation: The political origins of our time (2da Ed.). Boston: Beacon Press, 1957.

RHODES, R. A. Understanding governance: Policy networks, governance, reflexivity and accountability. London: Open University Press, 1997.

SCOTT, M. \& HARVEY, N. Translating science into coastal development decisions: The articulations science and planning in South Australia. Journal of Environmental Policy \& Planning, 2016, № 1, p. 85-101. https://doi.org/10.1080/1523908X.2015.1053108

SCOTT, M., BALAEV, M. \& CLARKE, B. Political embeddedness in environmental contexts: the intersections of social networks and planning institutions in coastal land use. Environmental Sociology, 2018, № 2, p. 286-298. https://doi.org/10.1080/23251042.2017.1374232

SOJA, E. Postmodern geographies: The reassertion of space in critical social theory. London: Verso, 1989.

SYKES, G. M. \& MATZA, D. Techniques of neutralization: A theory of delinquency. American Sociological Review, 1957, №22, p. 664-670. http://www.jstor.org/stable/2089195

TAUSSIK, J. The opportunities of spatial planning for integrated coastal management. Marine Policy, 2007, №31, p. 611-618. https://doi.org/10.1016/j.marpol.2007.03.006

VALLEJOS-ROMERO, A., BOSO, A., \& ZUNINO, HG. La relevancia de la confianza en conflictos socioambientales por energía en Chile: los casos de "Castilla" e "Hidroaysén". Revista de Geografía Norte Grande, 2016, № 63, p. 145-162. http://dx.doi.org/10.4067/S0718-34022016000100009

VILLAGRA, P., HERRMANN, G., QUNITANA, C. \& SEPULVEDA, RD. Resilience thinking and urban planning in a coastal environment at risks of tsunamis: the case study of Mehuín, Chile. Revista de Geografía Norte Grande, 2016, № 64, p. 63-82. http://dx.doi.org/10.4067/S0718-34022016000200006.

WHATMORE, SJ. Mapping knowledge controversies: Science, democracy and the redistribution of expertise. Progress in Human Geography, 2009, № 33, p. 587-598. https://doi. org/10.1177/0309132509339841

WHITE, R. Inventing Australia: Images and identity, 1688-1980. Sydney: Allen \& Unwin, 1981. 
